\title{
Studies regarding the quality of numerical weather forecasts of the WRF model integrated at high-resolutions for the Romanian territory
}

\author{
AMALIA IRIZA \\ University of Bucharest, Faculty of Physics, P.O. Box MG-11, Bucharest-Magurele, Romania; National \\ Meteorological Administration, Sos. Bucuresti-Ploiesti, nr. 97, Bucharest, Romania \\ Corresponding author; email: amalia.iriza@meteoromania.ro \\ RODICA C. DUMITRACHE \\ National Meteorological Administration, Sos. Bucuresti-Ploiesti, nr. 97, Bucharest, Romania
}

\begin{abstract}
AURELIA LUPASCU
National Meteorological Administration, Sos. Bucuresti-Ploiesti, nr. 97, Bucharest, Romania; Pacific Northwest National Laboratory, Richland, Washington

SABINA STEFAN

University of Bucharest, Faculty of Physics, P.O. Box MG-11, Bucharest-Magurele, Romania
\end{abstract}

Received: January 14, 2015; accepted: October 20, 2015

\begin{abstract}
RESUMEN
En este trabajo se evalúa la calidad de las predicciones meteorológicas del modelo numérico de alta resolución Weather Research and Forecasting (WRF). Las condiciones iniciales y de frontera fueron obtenidas del modelo numérico de predicción meteorológica regional Consortium for Small-scale Modeling (COSMO) con resolución horizontal de $7 \mathrm{~km}$. El modelo WRF fue integrado durante enero y julio de 2013 en dos resoluciones horizontales (3 y $1 \mathrm{~km}$ ). Las predicciones numéricas del modelo WRF se evaluaron utilizando diferentes medidas estadísticas calculadas para la temperatura a $2 \mathrm{~m}$ y para la velocidad del viento a $10 \mathrm{~m}$. Los resultados han mostrado una tendencia del modelo WRF a sobreestimar los valores de los parámetros meteorológicos analizados en comparación con las observaciones.
\end{abstract}

\begin{abstract}
The aim of this paper is to evaluate the quality of high-resolution weather forecasts from the Weather Research and Forecasting (WRF) numerical weather prediction model. The lateral and boundary conditions were obtained from the numerical output of the Consortium for Small-scale Modeling (COSMO) model at $7 \mathrm{~km}$ horizontal resolution. The WRF model was run for January and July 2013 at two horizontal resolutions ( 3 and $1 \mathrm{~km}$ ). The numerical forecasts of the WRF model were evaluated using different statistical scores for $2 \mathrm{~m}$ temperature and $10 \mathrm{~m}$ wind speed. Results showed a tendency of the WRF model to overestimate the values of the analyzed parameters in comparison to observations.
\end{abstract}

Keywords: Numerical modelling, high resolution, forecast verification, statistical scores.

\section{Introduction}

Limited area numerical models for short range forecast can be used for various research and op- erational forecasting applications. Despite recent improvements in model resolutions and advances in physical parameterizations, there are still limitations 
to the predictability possibilities offered by a limited area numerical model. Many questions regarding the performance of limited area models are related to the increase of the horizontal resolution of limited area numerical weather prediction models for short-range forecasts (Mass et al., 2002). Because some features of topographic circulations may require a smaller grid spacing to realistically simulate crucial structures, forecasts from high-resolution limited area models can have a higher accuracy than the global models. This is a result of the finer computational grid on a regional area, detailed specification of terrain and more detailed description of physical processes (WMO, 2012).

Recent research has shown that forecast accuracy increases with the decrease of grid spacing. Various studies done by Cardoso et al. (2012) and Heikkila et al. (2011) showed that high-resolution simulations are required especially for complex terrain, despite the high computational costs of such simulations. Adlerman and Droegemeier (2002) and Bernadet et al. (2000) indicated that some processes such as strong convection can only be captured when the resolution of the numerical model is decreased below $2 \mathrm{~km}$. Evaluations done over extended periods of time (Nachamkin and Hodur, 2000) have proven that increasing the horizontal resolution of weather prediction models improves numerical forecasts especially for integration domains with complex topographic features.

However, several points must be taken into account when performing high-resolution numerical simulations. An important limitation of the meteorological models at very high resolution is the inaccuracy of the real terrain representation because the data supplied by the model generally have a coarser resolution than the simulation domains (Lupascu et al., 2015), while Atlaskin and Vihma (2012) suggest that over an almost flat terrain horizontal resolution is not a major factor for the accuracy of $2 \mathrm{~m}$ temperature. Moreover, studies such as Zhong and Fast (2003) and Zhong et al. (2005) suggest that even in high-resolution numerical weather prediction (NWP) simulations forecast errors can still be quite large. A study conducted by Schepanski et al. (2015) showed that the choice of initial and boundary data have a greater impact on NWP simulations than the model grid resolution. Apart from this, high-resolution numerical simulations can sometimes prove to be less efficient due to cost limitations. The higher the resolution of the model, the higher the computational costs and storage space required for such numerical simulations (Morton et al., 2010, 2011).

The evaluation of high-resolution numerical simulations is itself affected by the limited availability and spatial density of meteorological observations (Gego et al., 2005).

In order to assess the quality of a numerical forecast we compare it with the corresponding observation or a good estimate of the true outcome. $\mathrm{Nu}-$ merical forecast verifications offer information about the nature of numerical forecast errors, the accuracy of the numerical forecasts and their improvement over time. Recommendations for numerical forecast verification methodologies were made by Stanski et al. (1989), Nurmi (2003), Wilks (2005), Jolliffe and Stephenson (2012).

The purpose of this study was to evaluate the quality of the numerical weather forecasts of the Weather Research and Forecasting (WRF) model (Skamarock et al., 2008) integrated at high-resolutions, coupled with the Consortium for Small-scale Modeling (COSMO) regional model (Schättler et al., 2012), for two different seasons. Brief descriptions of the model configuration and setup as well as the statistical methods employed for this study are given in section 2. The results of the study and their implications are discussed in section 3 . The paper ends with conclusions regarding the performance of the WRF model using initial and lateral boundary conditions from the COSMO model.

\section{Methodology}

For this study, the WRF model (version 3.4.1) with the ARW (Advanced Research WRF solver) as the dynamical core was run at $3 \mathrm{~km}$ horizontal resolution, using topography data at $3 \mathrm{~s}$ (approximately $90 \mathrm{~m}$ ) horizontal resolution. The topography data were obtained from the NASA Shuttle Radar Topographic Mission (SRTM, http://srtm.csi.cgiar.org/) database, which provides digital elevation data for over $80 \%$ of the globe. The data were entered in the WRF model for the studied domain, extending between $20.0-35.0^{\circ} \mathrm{E}$ and $40.0-50.0^{\circ} \mathrm{N}$.

The physical parameterizations used for this study include the Yonsei University (YSU) planetary boundary layer scheme (Hong and Dudhia, 2006), the WRF Single-Moment 5-class microphysics scheme (Hong et al., 2004), the 5-layer thermal diffusion land surface scheme (Chen and Dudhia, 2001), the Rapid 
Radiative Transfer Model (RRTM) scheme for longwave radiation (Mlawer and Clough, 1997), and the Dudhia (Dudhia, 1989) short-wave radiation scheme.

The output of the Consortium for Small-scale Modeling (COSMO) model at $7 \mathrm{~km}$ horizontal resolution (Schättler et al., 2012) was used as lateral and boundary conditions for the WRF numerical weather forecast model (Skamarock et al., 2008). The COSMO numerical model uses a rotated latitude/longitude grid. In order to use the output of the COSMO-7 km model for running the WRF model, a series of interpolation methods from rotated latitude/longitude grid into regular latitude/longitude grid were necessary.

The evaluation was carried out for two months, one during winter (January 2013) and one in the summer (July 2013). The WRF model was integrated independently (no feedback between the two integrations) at two horizontal resolutions ( 3 and $1 \mathrm{~km}$ ), for a domain which covered the entire Romanian territory with 261 ' 191 grid points $(3 \mathrm{~km})$ and $787^{\prime} 568$ grid points $(1 \mathrm{~km})$, respectively (presented in Fig. 1, outlined in red). The model was run for a $30 \mathrm{~h}$ forecast period with a spin-up period of $6 \mathrm{~h}$.

In order to assess the quality of the numerical weather forecast of the WRF model with COSMO lateral and boundary conditions (00:00 UTC run), we analyzed the ability of the model to forecast 2 $\mathrm{m}$ temperature and $10 \mathrm{~m}$ wind speed. Monthly and

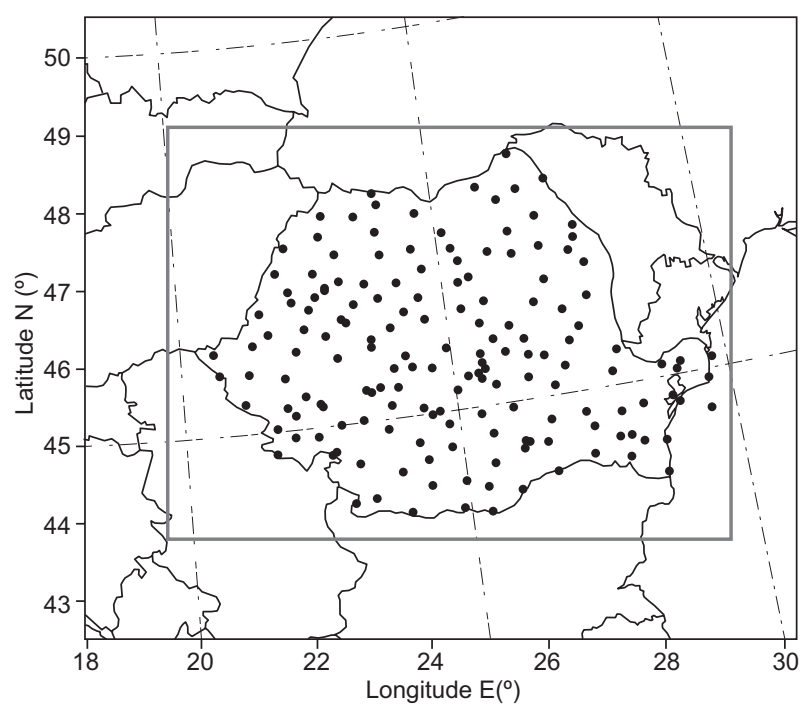

Fig. 1. WRF integration domain (outlined in a black rectangle) and location of meteorological stations used for verification (black dots). daily mean error (ME) and root mean square error (RMSE) were computed for both WRF-3 km and WRF-1 km taking into account all 163 Romanian synoptic stations (Fig. 1, black dots) which offer a very good coverage of the Romanian domain. The scores were computed for different forecast time steps (00:00 UTC $+6 \mathrm{~h}, 00: 00 \mathrm{UTC}+12 \mathrm{~h}$ and 00:00 $\mathrm{UTC}+18 \mathrm{~h})$. Also, in order to assess the ability of the WRF model to forecast the above mentioned parameters, scatter plots were used for a more detailed analysis of the correspondence between the forecasted values and the observations for $2 \mathrm{~m}$ temperatures and $10 \mathrm{~m}$ wind speed. The formulas for ME and RMSE are presented below in Eqs. (1) and (2), respectively (Stanski et al., 1989; Nurmi, 2003):

$$
\begin{aligned}
& M E=\frac{1}{N} \sum_{i=1}^{N}\left(F_{i}-O_{i}\right) \\
& R M S E=\sqrt{\frac{1}{N} \sum_{i=1}^{N}\left(F_{i}-O_{i}\right)^{2}}
\end{aligned}
$$

where $F_{i}$ represents the forecasts, $O_{i}$ are the corresponding observations and $N$ is the number of events.

\section{Results and discussion}

The general tendency of the WRF model to overestimate forecast values at both resolutions ( 3 and $1 \mathrm{~km}$ ) for $2 \mathrm{~m}$ temperature and $10 \mathrm{~m}$ wind speed in comparison with observations is also shown by the ME values for the two analyzed periods (Table I). As can be seen from ME values for $2 \mathrm{~m}$ temperature, the general tendency of both experiments (WRF-3 km and WRF-1 km) is to overestimate the forecasted values of this parameter in comparison with observations for the winter period analyzed. The same tendency can be noticed for the summer period for the 00:00 UTC $+6 \mathrm{~h}$ and for the 00:00 UTC $+12 \mathrm{~h}$ forecast. For the 00:00 UTC $+18 \mathrm{~h}$ forecast for the summer month, both models seemed to underestimate the values of the parameter in comparison with observations. For both months, differences in ME values between WRF-3 km and WRF-1 km vary between -0.06 deg C (for January 2013, 00:00 UTC + $6 \mathrm{~h}$ and 00:00 UTC $+12 \mathrm{~h}$ ) and 0.29 deg C (July 2013, 00:00 UTC $+6 \mathrm{~h}$ and 00:00 UTC $+12 \mathrm{~h}$ ). Despite the high values of RMSE for both months, errors of smaller amplitude can be noticed for WRF-1 km than for WRF$3 \mathrm{~km}$ for most of the analyzed period.

Daily ME and RMSE values were computed for WRF-3 km and WRF-1 km for the same forecast 
Table I. Two-meter temperature and $10 \mathrm{~m}$ wind speed mean error (ME) and root mean square error (RMSE) values for January 2013 and July 2013 (in deg C and $\mathrm{ms}^{-1}$, respectively), for different time steps (00:00 UTC $+6 \mathrm{~h}, 00: 00 \mathrm{UTC}+12 \mathrm{~h}$ and 00:00 $\mathrm{UTC}+18 \mathrm{~h}$ ), for both integration domains.

\begin{tabular}{|c|c|c|c|c|c|c|}
\hline \multirow[b]{2}{*}{ Date } & \multirow[b]{2}{*}{ Score } & \multirow{2}{*}{$\begin{array}{l}\text { Forecast } \\
\text { time }\end{array}$} & \multicolumn{2}{|c|}{ WRF-3 km } & \multicolumn{2}{|c|}{ WRF-1 km } \\
\hline & & & $\begin{array}{c}\mathrm{T} 2 \mathrm{~m} \\
(\operatorname{deg} \mathrm{C})\end{array}$ & $\begin{array}{c}\text { WS10m } \\
\left(\mathrm{ms}^{-1}\right)\end{array}$ & $\begin{array}{c}\mathrm{T} 2 \mathrm{~m} \\
(\operatorname{deg} \mathrm{C})\end{array}$ & $\begin{array}{c}\mathrm{WS} 10 \mathrm{~m} \\
\left(\mathrm{~ms}^{-1}\right)\end{array}$ \\
\hline \multirow{6}{*}{$\begin{array}{l}\text { January } \\
2013\end{array}$} & \multirow{3}{*}{$\mathrm{ME}$} & 06 & 1.85 & 0.91 & 1.91 & 0.73 \\
\hline & & 12 & 2.02 & 1.38 & 2.14 & 1.22 \\
\hline & & 18 & 2.39 & 1.14 & 2.45 & 1.03 \\
\hline & \multirow{3}{*}{ RMSE } & 06 & 2.77 & 2.09 & 2.73 & 2.03 \\
\hline & & 12 & 2.92 & 2.41 & 2.93 & 2.30 \\
\hline & & 18 & 3.11 & 2.35 & 3.08 & 2.26 \\
\hline \multirow{6}{*}{$\begin{array}{l}\text { July } \\
2013\end{array}$} & \multirow{3}{*}{$\mathrm{ME}$} & 06 & 0.49 & 0.79 & 0.78 & 0.72 \\
\hline & & 12 & 0.27 & 0.72 & 0.56 & 0.73 \\
\hline & & 18 & -1.69 & 0.25 & -1.61 & 0.58 \\
\hline & \multirow{3}{*}{ RMSE } & 06 & 2.27 & 1.86 & 2.30 & 1.79 \\
\hline & & 12 & 2.14 & 1.86 & 2.04 & 1.91 \\
\hline & & 18 & 2.87 & 1.78 & 2.62 & 1.91 \\
\hline
\end{tabular}

T2m: 2 m temperature; WS10 m: 10-m wind speed; ME: mean error; RMSE: root mean square error.

times mentioned above and are represented in Figs. 2-7. For $2 \mathrm{~m}$ temperature, slightly smaller daily error values can be noticed for WRF-3 km compared to WRF-1 km for most of January 2013. However, smaller amplitude of errors is generally obtained from WRF-1 km for this period. Again, the tendency of the model to overestimate forecast values compared to observations is obvious for January 2013 for all analyzed forecast times (Figs. 2-4).

For July 2013, the same behavior of overestimation can be noticed for the 00:00 UTC $+6 \mathrm{~h}$ forecast time, both for the WRF-3 km and WRF-1 km forecasts for most of the period (Fig. 2).

For the first part of the same period, the values of these scores computed for the 00:00 UTC $+12 \mathrm{~h}$ forecast time also show the same tendency to overestimate forecasted values of $2 \mathrm{~m}$ temperature compared to observations taking into account the WRF model integrated at both horizontal resolutions (Fig. 3). The analysis of ME and RMSE values for the same forecast time $(00: 00 \mathrm{UTC}+12 \mathrm{~h})$ for the second part of July 2013, shows that WRF-1 km and especially WRF-3 km tend to underestimate forecasted values of this parameter in comparison to the observations from the meteorological sites (Fig. 3).
For the last forecast time analyzed here (00:00 UTC +18 h, Fig. 4), the general tendency of the WRF model integrated at both horizontal resolutions is to overestimate forecasted $2 \mathrm{~m}$ temperature values compared to the observed ones for the entire month of January and to underestimate them for July. From Figure 3 it is also observed that the very small ME monthly value obtained previously for the 00:00 $\mathrm{UTC}+12 \mathrm{~h}$ forecast time for July 2013 with the WRF-3 km model was due to compensating errors (overestimation for the first half of the month and underestimation for the second half).

In Figures 5-7, $10 \mathrm{~m}$ wind speed daily ME and RMSE for January 2013 and July 2013 are represented for the three analyzed forecast steps (00:00 UTC + $6 \mathrm{~h}, 00: 00 \mathrm{UTC}+12 \mathrm{~h}, 00: 00 \mathrm{UTC}+18 \mathrm{~h}$ ), for both WRF-3 $\mathrm{km}$ and WRF-1 km. It can be noticed that in a small number of cases, both models (WRF- $3 \mathrm{~km}$ in particular) forecasted smaller values for $10 \mathrm{~m}$ wind speed than the observed values for the 00:00 UTC + $18 \mathrm{~h}$ lead times (Fig. 7). Apart from these few cases, the general tendency of both WRF-3 km and WRF-1 $\mathrm{km}$ is to overestimate the values for this parameter compared to the observations for all forecast times analyzed. 
(a)

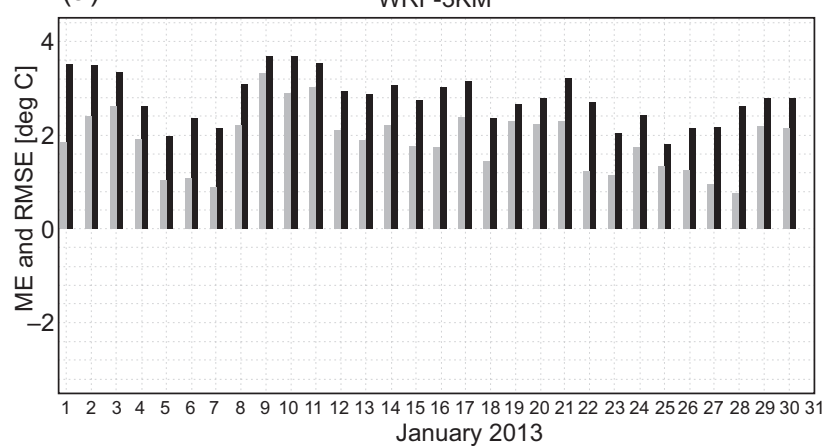

(c)

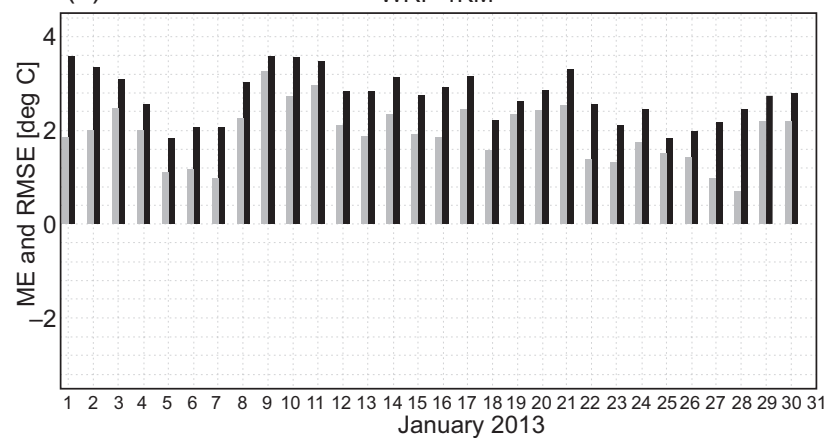

(b)

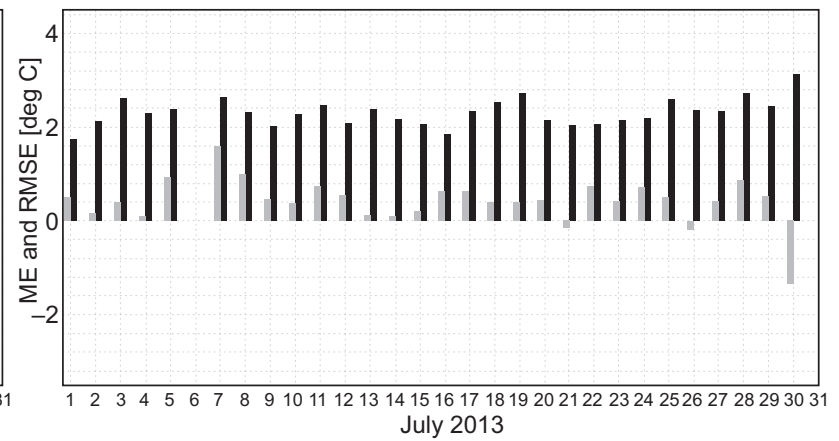

(d)

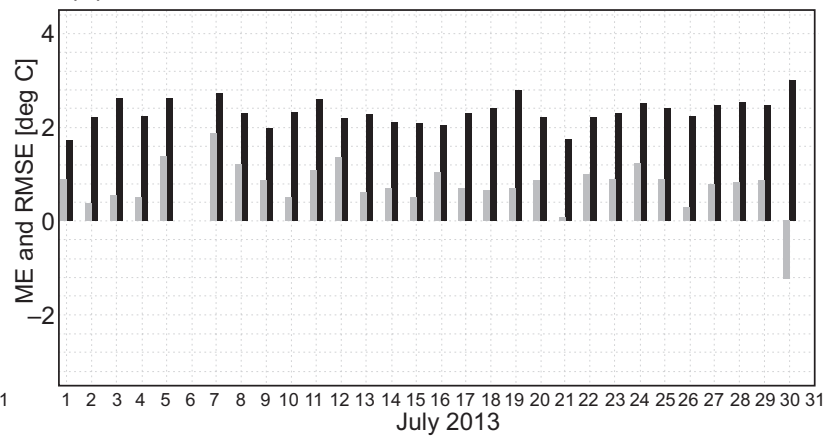

IME IRMSE

Fig. 2. $2 \mathrm{~m}$ temperature ME (in light gray) and root RMSE (in black) in deg C for January 2013 (left) and July 2013 (right), 00:00 UTC $+6 \mathrm{~h}$. WRF-3 km (first row) and WRF-1 km (second row).

(a)

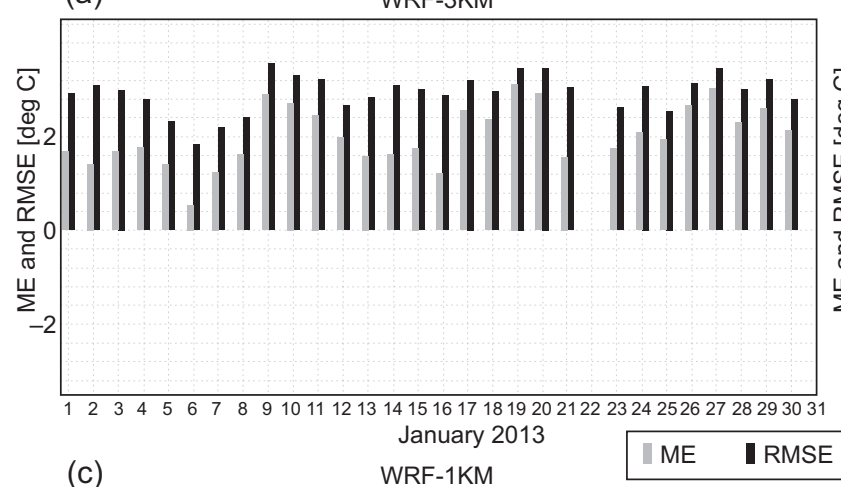

(b)

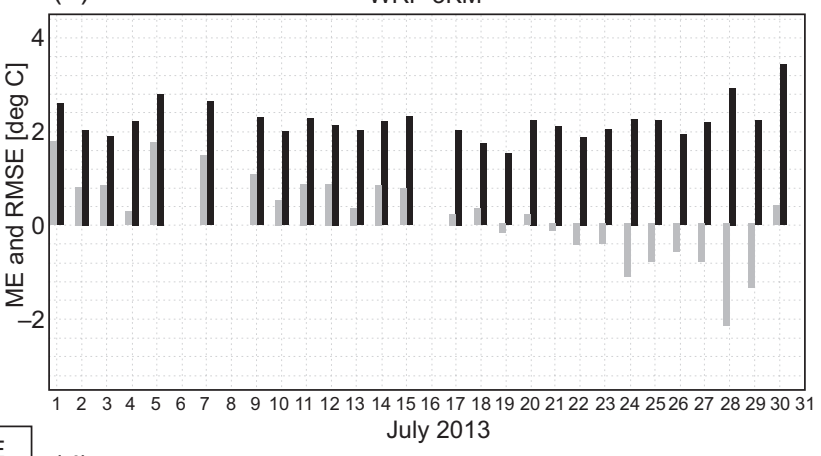

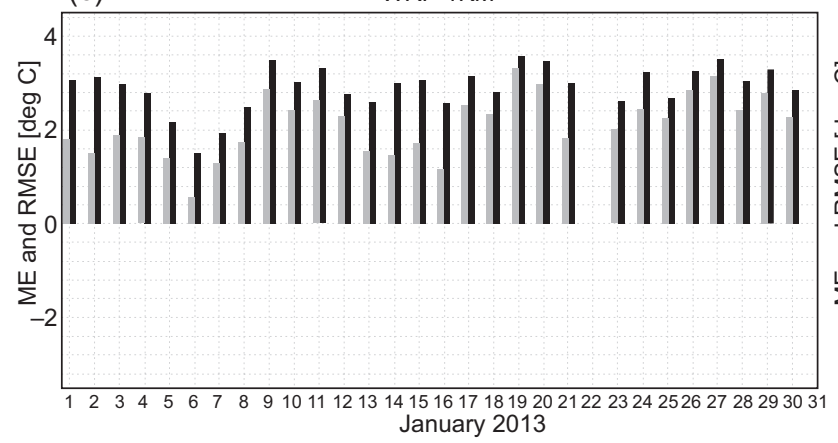

(d) WRF-1KM

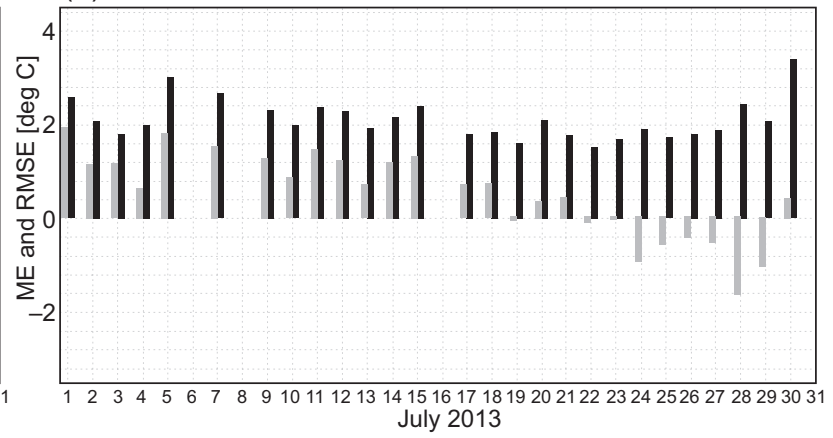

Fig. 3. 2 m ME (in light gray) and RMSE (in black) in deg C for January 2013 (left) and July 2013 (right), 00:00 UTC $+12 \mathrm{~h}$. WRF-3 km (first row) and WRF-1 km (second row). 
(a)

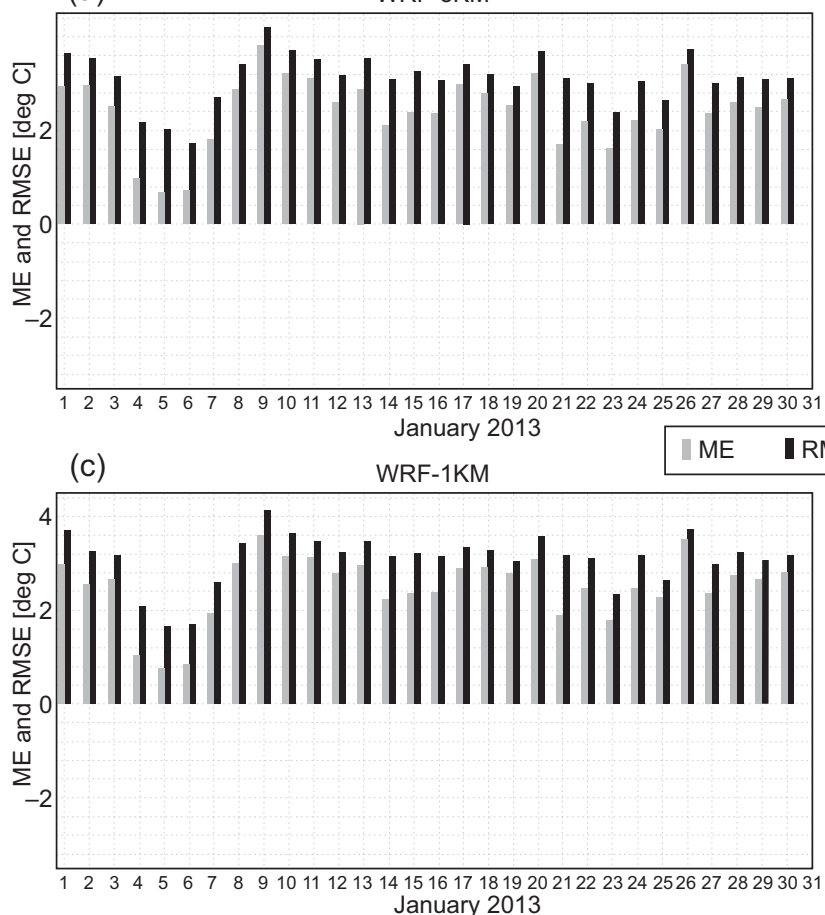

(b)

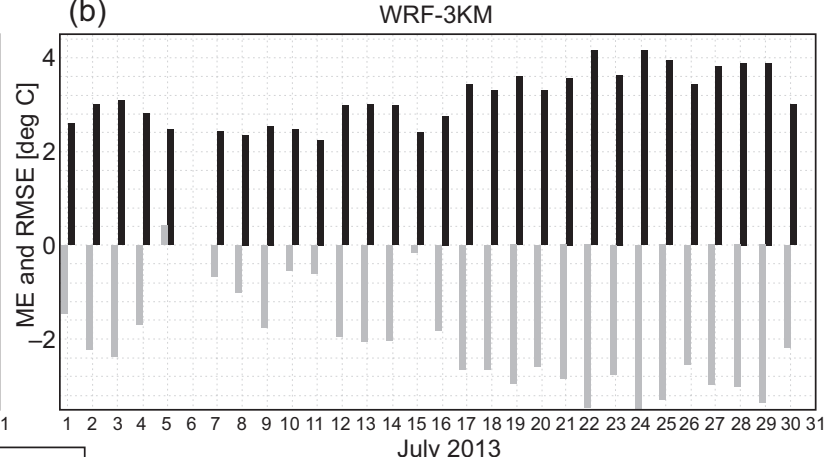

July 2013

WRF-1KM

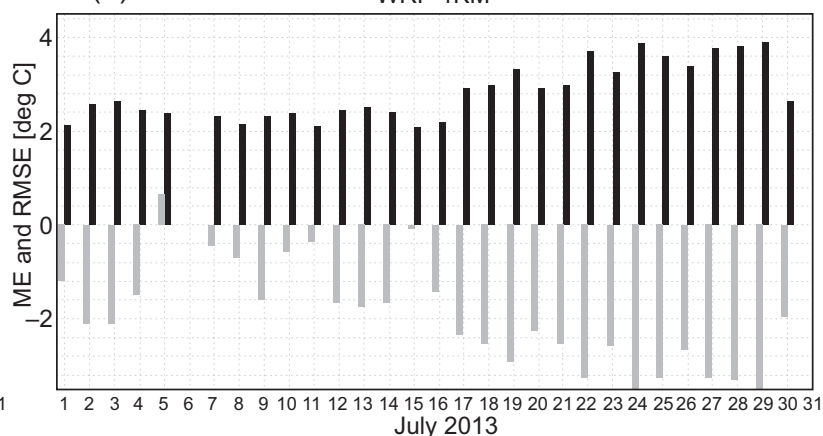

Fig. 4. $2 \mathrm{~m}$ temperature ME (in light gray) and RMSE (in black) in deg C for January 2013 (left) and July 2013 (right), 00:00 UTC + $18 \mathrm{~h}$. WRF-3 km (first row) and WRF-1 km (second row).

(a)

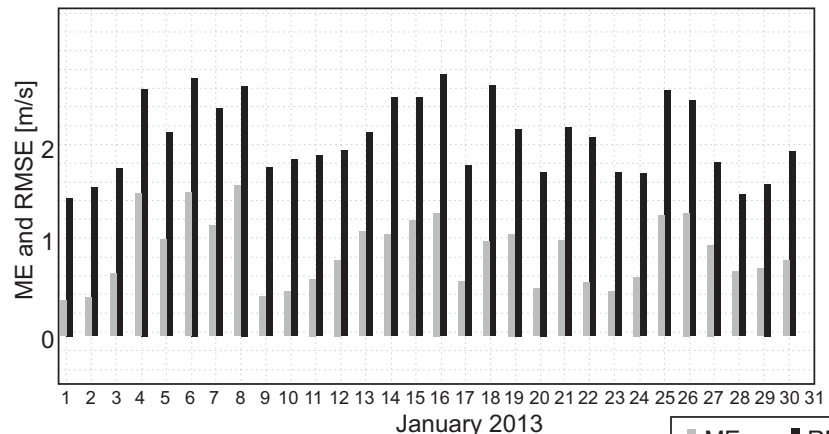

(b)

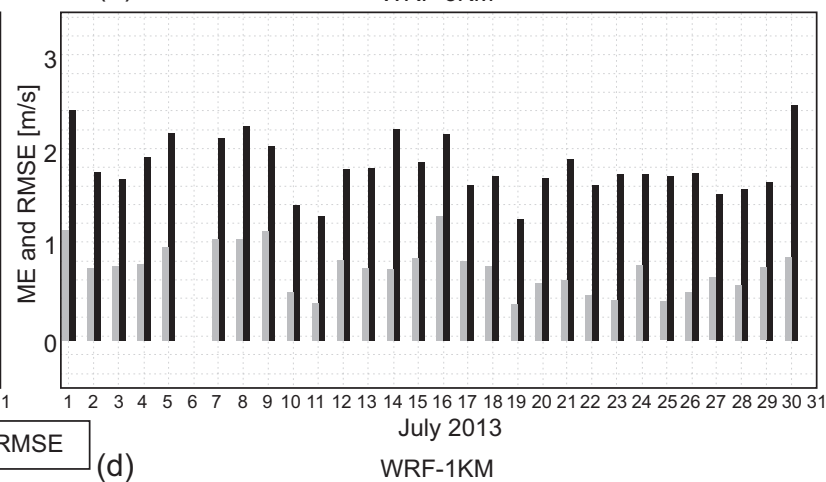

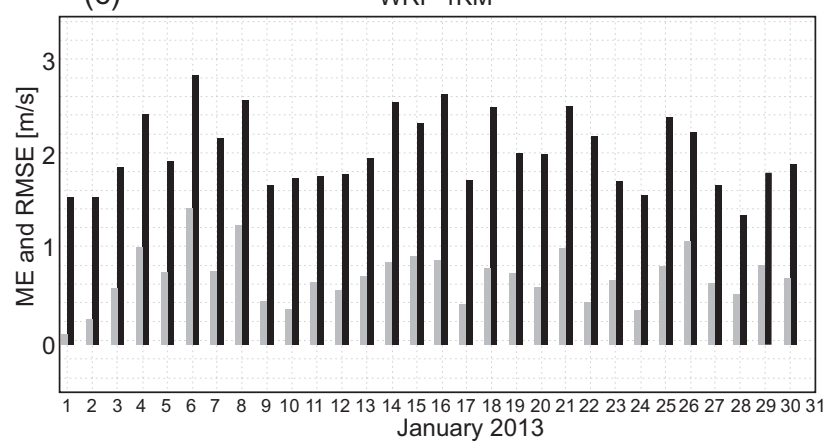

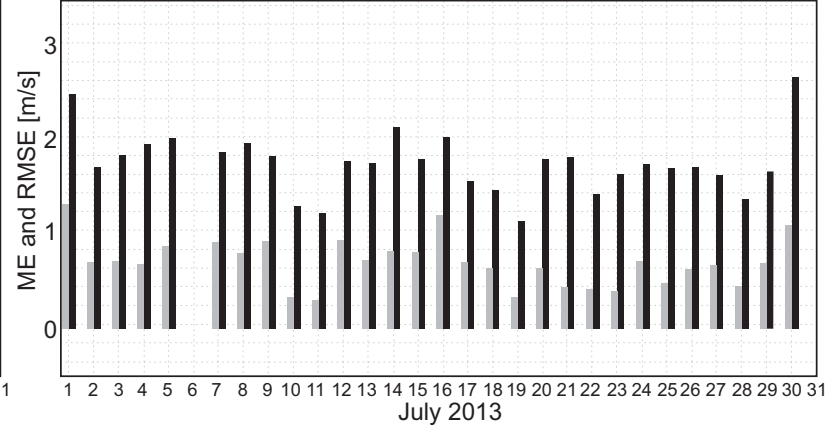

Fig. 5. $10 \mathrm{~m}$ wind speed ME (in light gray) and RMSE (in black) in $\mathrm{ms}^{-1}$ for January 2013 (left) and July 2013 (right), 00:00 UTC +6 h. WRF-3 km (first row) and WRF-1 km (second row) 
(a)

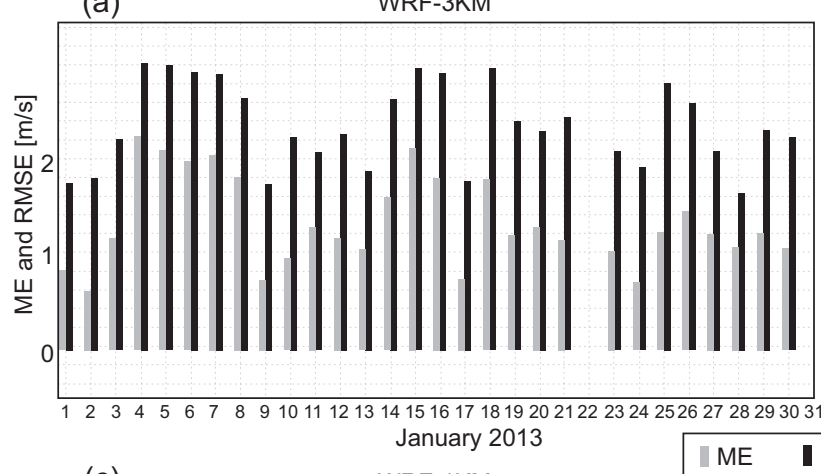

(c)

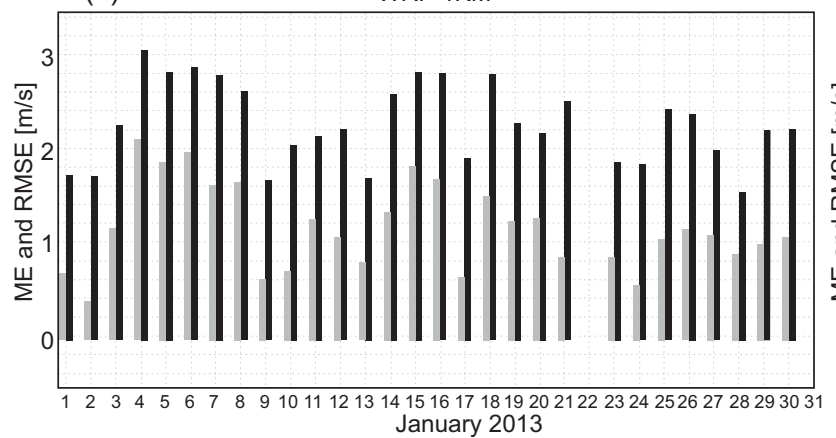

(b)

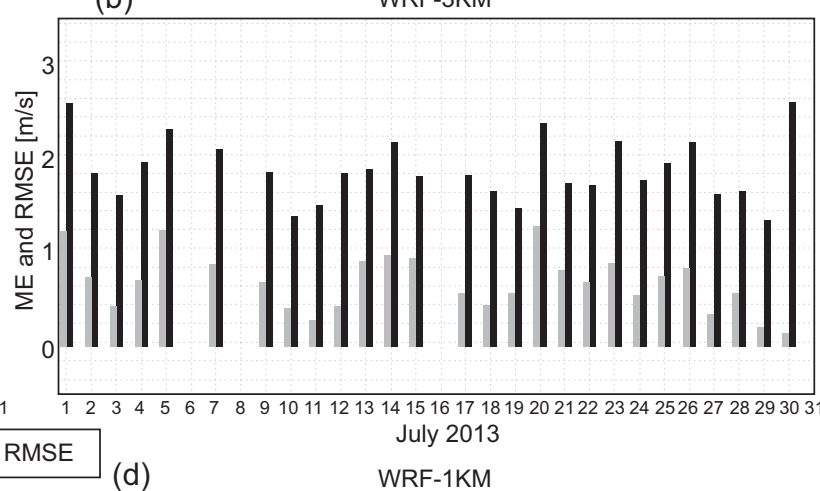

Fig. 6. $10 \mathrm{~m}$ wind speed ME (in light gray) and RMSE (in black) in $\mathrm{ms}^{-1}$ for January 2013 (left) and July 2013 (right), 00:00 UTC + $12 \mathrm{~h}$. WRF-3 km (first row) and WRF-1 km (second row).

(a)

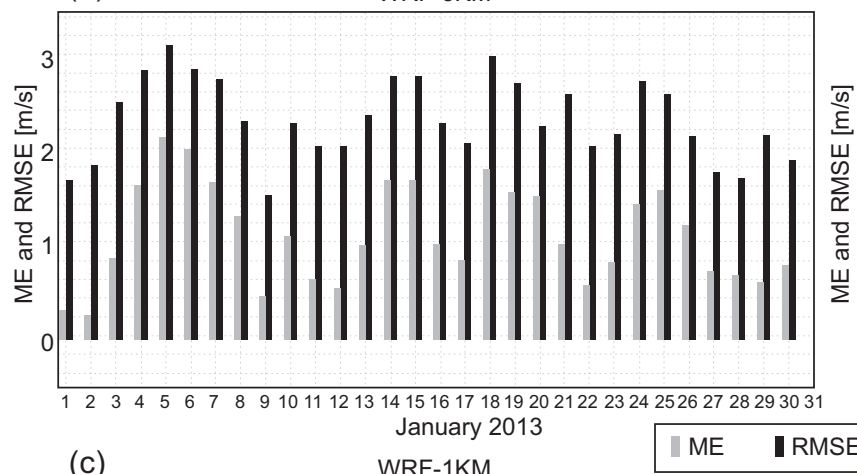

(b)

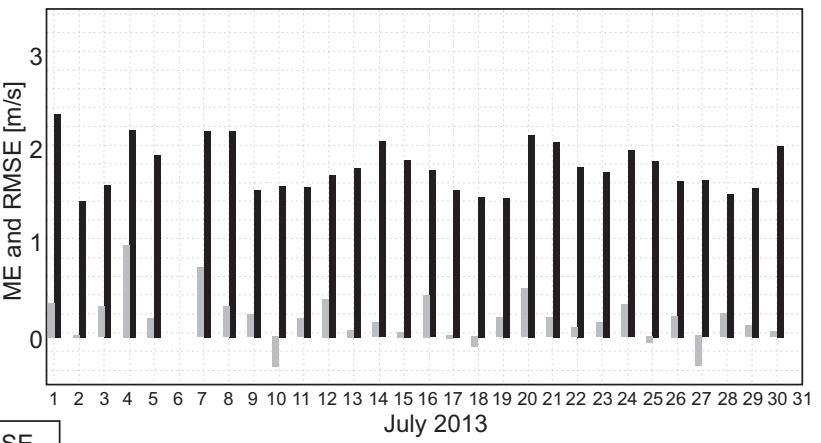

(d)

WRF-1KM
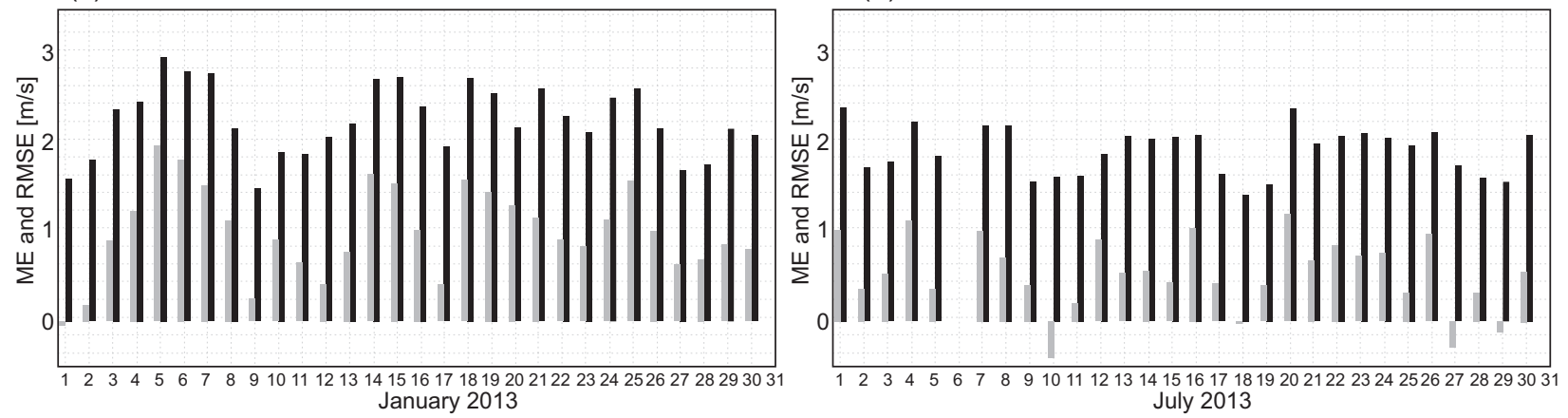

Fig. 7. $10 \mathrm{~m}$ wind speed ME (in light gray) and RMSE (in black) in $\mathrm{ms}^{-1}$ for January 2013 (left) and July 2013 (right), 00:00 UTC + $18 \mathrm{~h}$. WRF-3 km (first row) and WRF-1 km (second row). 

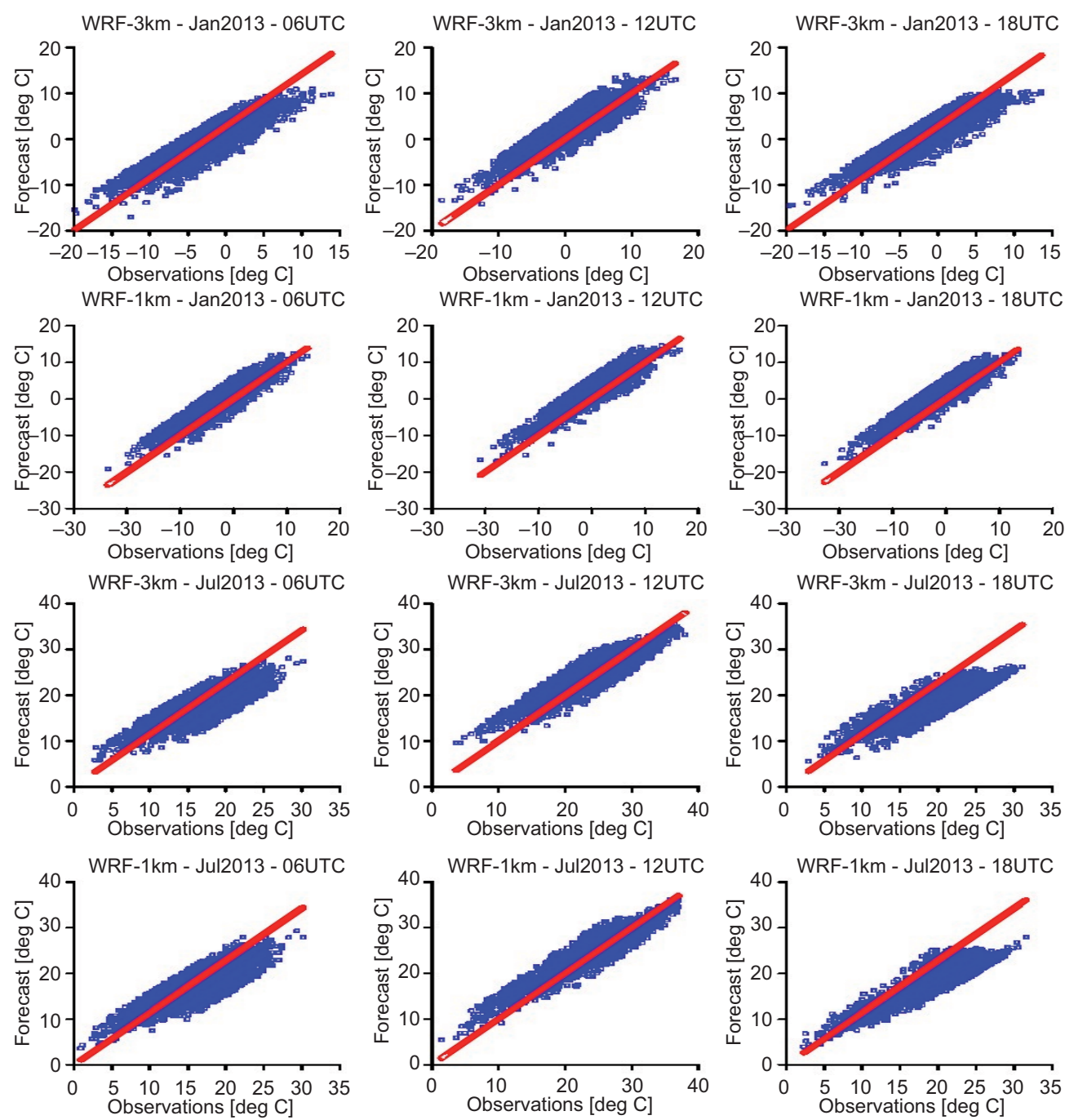

Fig. 8. Scatter plots for $2 \mathrm{~m}$ temperature (in deg C) - January 2013 (first two rows) and July 2013 (last two rows), for different time steps (00UTC $+6 \mathrm{~h}-$ left, 00:00 UTC $+12 \mathrm{~h}-$ center, 00:00 UTC $+18 \mathrm{~h}$ - right), for WRF-3 km (first and third rows) and WRF-1 km (second and fourth rows).

In the scatter plots for $2 \mathrm{~m}$ temperature, forecast values are represented against the observed values (Fig. 8). As can be seen from Figure 8, at all forecast times during the entire period, many of the points represented are on or very close to the diagonal. The spread of the points shows a high accuracy of both WRF-3 km and WRF-1 km model forecasts for $2 \mathrm{~m}$ temperature. However, as previously seen from the ME and RMSE values computed for both models, the scatter plots show the same tendency of WRF$3 \mathrm{~km}$ and WRF-1 km, that is, to overestimate the forecasted values in comparison to the observed ones for this parameter for January 2013 (all forecast times), July 2013 (00:00 UTC +6 h forecast time) and the first part of July 2013 (00:00 UTC + $12 \mathrm{~h}$ forecast time) and underestimate them for the remaining period $(00: 00 \mathrm{UTC}+18 \mathrm{~h})$ and the entire July period (00UTC $+18 \mathrm{~h}$ ).

Also, it can be noticed that the spread of the WRF-1 km is slightly better than that for WRF-3 km, especially in the case of the forecast for January 2013 and the 00:00 UTC $+12 \mathrm{~h}$ forecast for July 2013 .

The scatter plots in Figure 9 show the spread of the forecast-observation errors for $10 \mathrm{~m}$ wind speed. The spread of the errors close to 0 indicate a high accuracy of both WRF-3 km and WRF-1 km in forecasting this parameter. A slightly greater spread of the errors as well as a stronger overestimation of the forecasted 

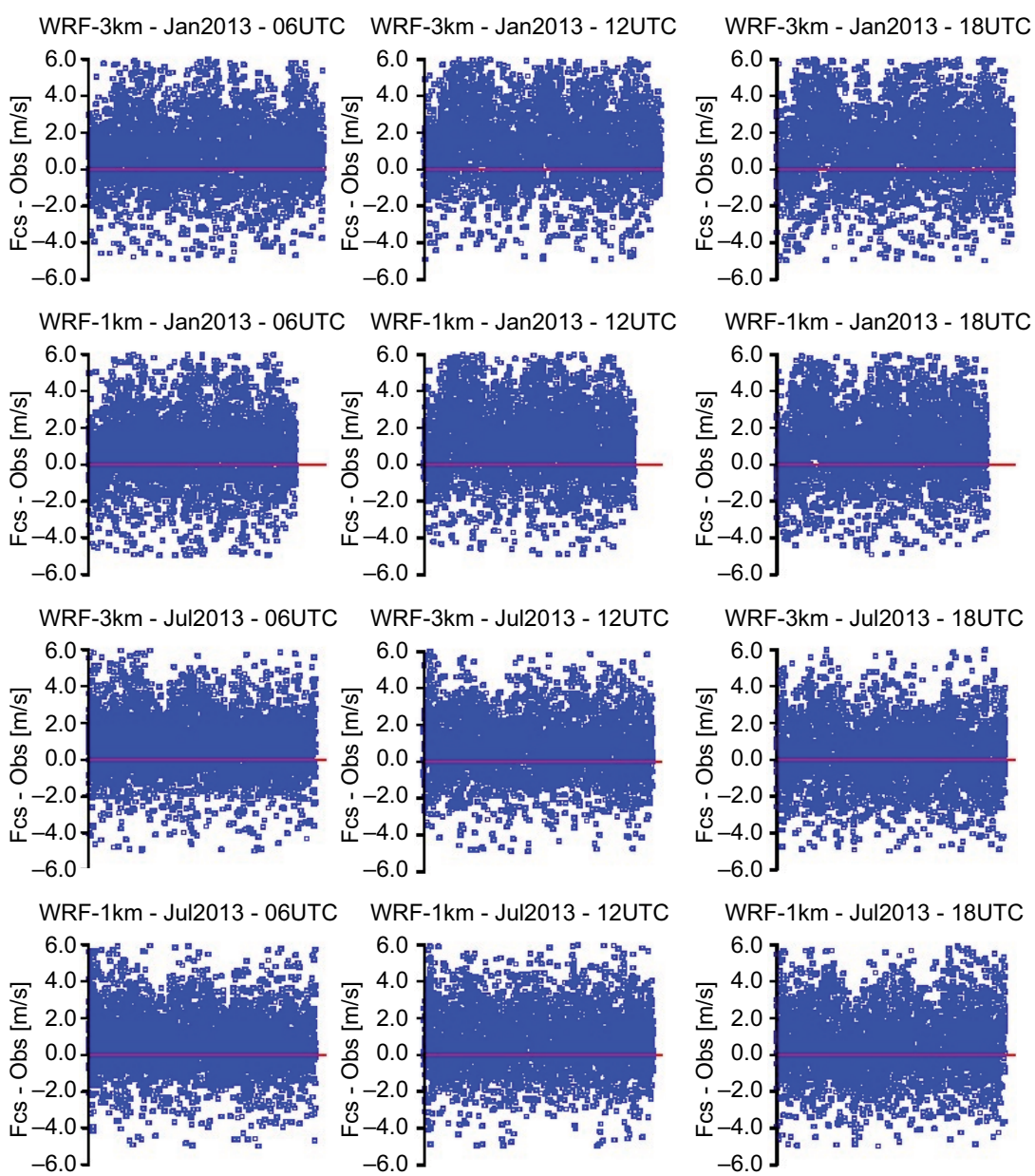

Fig. 9. Scatter plots for errors in $10 \mathrm{~m}$ wind speed (in $\mathrm{ms}^{-1}$ ). January 2013 (first two rows) and July 2013 (last two rows), for different time steps (00:00 UTC + $6 \mathrm{~h}$ - left, 00:00 UTC $+12 \mathrm{~h}$ - center), and 00:00 UTC $+18 \mathrm{~h}$ - right, for WRF-3 km (first and third rows) and WRF-1 km (second and fourth rows).

values vs. observations can be noticed for WRF-3 km compared to WRF-1 km. These results, as well as the ones shown above indicate a better performance from both WRF-3 $\mathrm{km}$ and WRF- $1 \mathrm{~km}$ for the summer period analyzed in this study (July 2013) than for the winter period. It can also be noticed that for the same periods and forecast times the models have a similar behavior in that they both either underestimate or overestimate the values forecasted for $2 \mathrm{~m}$ temperature or $10 \mathrm{~m}$ wind speed in comparison with observed values.

\section{Conclusions}

The purpose of this study is to evaluate the quality of the numerical weather forecasts of the WRF model integrated at two high resolutions.
The analysis of ME and RMSE for January 2013 and July 2013 indicate that the numerical weather forecast of the high-resolution WRF model for the $2 \mathrm{~m}$ temperature and $10 \mathrm{~m}$ wind speed parameters show differences depending on the forecast time and the horizontal resolution of the model.

For the present study, the WRF model was run with high-resolution topography data and lateral and boundary conditions from the limited area COSMO-7 km model, using a standard configuration of the parameterization schemes available in the WRF model.

A first analysis of the results obtained in this study shows a good quality of the numerical forecasts from the WRF model integrated at high resolutions for Romanian territory. 
The analysis of scatter plots for $2 \mathrm{~m}$ temperature and $10 \mathrm{~m}$ wind speed forecast from the WRF-3 km and WRF-1 km show a good correspondence between the model forecasts and the observed values for these parameters. This indicates a good accuracy of the model run at both horizontal resolutions, despite the general tendency of the WRF-3 km and WRF-1 km to overestimate the forecasted values in comparison to observations. It is also important to notice a similar behavior of WRF-3 km and WRF-1 km for the same periods and forecast times.

Results indicate a slightly better performance from the WRF-1 km model compared to the WRF-3 $\mathrm{km}$ model. Also, a better performance for both models can be noticed for the summer period analyzed in this paper.

Taking into account the model set-up employed in the present study, other improvements of the numerical weather forecasts of the high-resolution WRF model for Romanian territory can be further obtained by integrating this model using different parameterization schemes.

\section{References}

Adlerman E. J. and K. Droegemeier, 2002. The sensitivity of numerically simulated cyclic mesocyclogenesis to variations in model physical and computational parameters. Mon. Weather Rev. 130, 2671-2691.

Atlaskin E. and T. Vihma, 2012. Evaluation of NWP results for wintertime nocturnal boundary-layer temperatures over Europe and Finland. Q. J. R. Meteorol. Soc. 138, 1440-1451, doi:10.1002/qj.1885.

Bernadet L. R., L. D. Grasso, J. E. Nachamkin, C. A. Finley and W. R. Cotton, 2000. Simulating convective events using a high-resolution mesoscale model. J. Geophys. Res. 105, 14963-14982.

Cardoso R. M., P. M. M. Soares, P. M. A. Miranda and M. Belo-Pereira, 2012. WRF high resolution simulation of Iberian mean and extreme precipitation climate. Int. J. Climatol. 33, 2591-2608.

Chen F. and J. Dudhia, 2001. Coupling and advanced land surface-hydrology model with the Penn StateNCAR MM5 modeling system. Part I: Model implementation and sensitivity. Mon. Weather Rev. 129, 569-585.

Dudhia J., 1989. Numerical study of convection observed during the winter monsoon experiment using a mesoscale two-dimensional model. J. Atmos. Sci. 46, 3077-3107.
Gego E., C. Hogrefe, G. Kallos, A. Voudouri, J. S. Irwin and S. T. Rao, 2005. Examination of model predictions at different horizontal grid resolutions. Environ. Fluid Mechan. 5, 63-85.

Heikkila U., A. Sandvik and A. Sorterberg, 2011. Dynamical downscaling or ERA-40 in complex terrain using WRF regional climate model. Clim. Dynam. 37, 1551-1564.

Hong S.-Y., J. Dudhia and S.-H. Chen, 2004. A revised approach to ice microphysical process for the bulk parameterization of cloud and precipitation. Mon. Weather Rev. 132, 103-120.

Hong S.-Y. and J. Dudhia, 2006. A new vertical diffusion package with an explicit treatment of entrainment processes. Mon. Weather Rev. 134, 2318-2341.

Jolliffe I. T. and D. B. Stephenson, 2012. Forecast verification: A practitioner's guide in atmospheric science, 2nd ed. Wiley and Sons Ltd, Chichester, 274 pp.

Lupascu A., A. Iriza and R. C. Dumitrache, 2015. Using a high resolution topographic data set and analysis of the impact on the forecast of meteorological. Rom. Rep. Phys. 67, 653-664.

Mass C. F., D. Ovens, K. Westrick and B. A. Colle, 2002. Does increasing horizontal resolution produce more skillful forecasts? Bull. Amer. Meteor. Soc. 83, 407-430.

Mlawer E. and S. Clough, 1997. Shortwave and longwave radiation enhancements in the rapid radiative transfer model. 7th Atmospheric Radiation Measurement (ARM) Science team Meeting ARM-CONF, San Antonio, Texas, 3-7 March.

Morton D., O. Nudson, D. Bahls and G. Newby, 2010. Pushing WRF to its computational limits. 2010 Alaska Weather Symposium, Fairbanks, Alaska, March.

Morton D., O. Nudson, D. Bahls, P. Johnsen, D. Arnold, I. Schicker, 2011. Grand-scale WRF testing on the Cray XT5 and XE6. Cray User Group Proceedings, Fairbanks, Alaska, 23-26 May.

Nachamkin J. E. and R. M. Hodur, 2000. Verification of short-term forecasts from the Navy COAMPS over the Mediterranean. 15th Conference on Statistics and Probability in the Atmospheric Sciences, Asheville, North Carolina, 8-11 May.

Nurmi P., 2003. Recommendations on the verification of local weather forecasts (at ECWMF member states). ECMWF Operations Department, Reading, 19 pp.

Schättler U., G. Domms and C. Schraff, 2012. A description of the non-hydrostatic regional COSMO-model. Part VII: Users guide. Technical report. DWD, Offenbach, 190 pp. 
Schepanski K., O. Knippertz, S. Fiedler, F. Timouk and J. Demarty, 2015. The sensitivity of nocturnal low-level jets and near-surface winds over the Sahel to model resolution, initial conditions and boundary-layer set-up. Q.J. R. Meteorol. Soc. 141, 1442-1456, doi:10.1002/qj.2453.

Skamarock W., J. B. Klemp, J. Dudhia, D. Gill, D. M. Baker, M. Duda, X.-Y. Huang, W. Wang and J. G. Powers, 2008. A description of the Advanced Research WRF version 3. NCAR technical note NCAR/TN-475+STR. National Centers for Atmospheric Research, Boulder, $113 \mathrm{pp}$.

Stanski H. R., L. J. Wilson, and W. R. Burrows, 1989. Survey of common verification methods in meteorology. World Weather Watch Tech. Rept. No.8, WMO/ TD No.358, World Meteorological Organization, Geneva, 114pp.
Wilks D. S., 2005. Statistical Methods in the Atmospheric Sciences, 2nd Edition. Elsevier, 627pp.

WMO, 2012. Statement of guidance for high-resolution numerical weather prediction (T. Montmerle, Ed.). WMO Statement of Guidance. World Meteorological Organization, Geneva, 7 pp.

Zhong S. and J. Fast, 2003. An evaluation of the MM5, RAMS, and Meso-Eta models at subkilometer resolution using VTMX Field Campaign data in the Salt Lake Valley. Mon. Weather Rev. 131, 1301-1322.

Zhong S., H.-J. In, X. Bian, J. Charney, W. Heilman and B. Potter, 2005. Evaluation of real-time high-resolution MM5 predictions over the Great Lakes region. Weather Forecast. 20, 63-81, doi:10.1175/WAF-834.1. 